\title{
Recent work of the Conference of European statisticians
}

1. Work Session on Marine Water Quality Statistics (Geneva, 10-12 February 1992)

The session agreed on a tentative draft of a statistical classification of marine water quality. It is planned to refine this classification further and to organize tests, before it will be finally approved by the Conference of European Statisticians (CES/716).

\section{Work session on Housing Statistics (Geneva, 9-11 March 1992)}

The meeting reviewed preliminary proposals of possible additions to the European Programme of Current Housing, Building and Planning Statistics concerning distributional aspects of housing statistics and data on the condition of the dwelling stock and on housing improvements, repairs and maintenance. The views expressed by the participants will be taken into account in preparing the draft text of the new Programme, which will be reviewed by countries at a meeting on housing statistics scheduled to be held in Geneva in the Spring of 1993 (CES/731).

3. Work Session on Statistical Data Editing (Washington, D.C., 23 to 27 March 1992)

The work session considered problems dealing with data editing methods and techniques focusing on data editing costs and collection of data from administrative sources. QUID (France), CASOC (UK), SPEER, PEDRO, ARIES (U.S.A.) have been presented and discussed.

\section{Work Session on Statistics of Women (Geneva, 27-29 April 1992)}

The participants discussed issues concerned with measuring the economic contributions of women through time-use surveys and other sources, and the use of innovative approaches with existing statistics to throw light on aspects of the situation of women that are not readily apparent in existing statistics. They also 
reviewed plans for a proposed future statistical publication on women in the ECE region (CES/730).

5. Work Session on Population and Housing Censuses (Geneva, 4-6 May 1992)

This meeting discussed (i) uses made of census data; (ii) public acceptance of censuses; (iii) directing census products more towards users' needs; (iv) recent developments in census data dissemination; and (v) alternatives to censuses and censustype statistics (CES/729).

6. A Work Session on Energy Statistics (Geneva, 11-13 May 1992)

The meeting discussed improvements and harmonizations in ECE energy bulletins as well as in international energy statistics. Recommendations for further work of the Conference in that area were made (CES/732).

7. Work Session on Waste and Recycling Statistics (Geneva, 18-20 May 1992)

The meeting permitted to draw conclusions from the test of the draft ECE Standard Statistical Classification of Wastes, which was used during data collection for the 1992 ECE Compendium of Environmental Statistics. The work session was organized jointly with Eurostat and assessed the problems that need to be solved on the road towards a single international classification of wastes (CES/734).

\section{Origin-destination matrices of international migration flows among countries in the ECE region, 1987 to 1990}

Annual Statistics on immigration and emigration for the years 1987 to 1990 were collected from countries, arranged in matrix form and distributed to countries. Statistics for the first three years were published in document CES/710, and for 1990 in CES/728. 